\title{
TRANSFERABLE SKILLS: FROM WORK TO SCHOOL
}

\author{
Haaniyah Ali and Jeffrey Harris \\ Lassonde School of Engineering, York University \\ haaniyah@my.yorku.ca,jpharris@yorku.ca
}

\begin{abstract}
The focus of this project is on finding key skills that have been developed and/or transferred to the workplace from previous school experience, and how these relate back to a student's school term. Following a phenomenological approach, this paper explores three case studies and tracks various skills from their coop term into their school term. The most transferable skills were communication, time management, organization, responsibility and problem solving. Some students also specified skills such as diligence, focus and the need for initiative as vital for a successful work placement. One consistency was that students did not find that their technical skills transferred between terms, but rather that there was far more emphasis and transferability of general skills. Therefore, general skills were the most transferable, both to and from the workplace. Finally, students mentioned the applications of skills to clubs, indicating the importance of extracurriculars in a student's educational experience.
\end{abstract}

Keywords: general skills, soft skills, technical skills, transferability, co-operative education, engineering, workintegrated learning

\section{INTRODUCTION}

According to co-operative Education and Workintegrated Learning (CEWIL) Canada, work-integrated learning (or co-op, as described here) is a program designed to integrate "a student's academic studies and learning in a workplace or practise setting" [1]. Throughout the years, co-op programs have grown and changed for degree specifications; still, there is a lack of understanding of what skills are specifically gained from such programs, as well as where they may derive from and how a student may apply this knowledge [2]. This means that it is important for further research to be done, to better understand how exactly co-operative education programs help students. This project aims to fill some of these knowledge gaps and highlight select vital skills.

This research project explores the skills utilized and transferred during a work placement term. Three students were interviewed, each two times, and were selected individually. Each of these interviews has been one-on-one and all of these students have been upper-year mechanical engineering undergraduates. The focus was on finding the key skills that had been developed and/or transferred to their workplace from previous school experience, and how these skills transfer back into the school term. For the scope of this project, general skills (also referred to as soft or professional skills in some literature) are interpersonal skills that transcend theoretical or degree-specific knowledge. These skills include organization, responsibility, communication, etc. Skills such as diagram analysis, 3D modelling, technical drawing, etc are considered technical skills in the scope of this study.

The framework followed in this process was phenomenology, in which the lived experienced was highlighted. This means that students were asked not to view their experiences from a reflective lens after the experience. Each interview was tailored to understand the student's current situation, and the questions were asked critically. There were elements relating to reliving past experiences (i.e. students were asked about previous school experiences during their work term), but these questions were tailored to be matter-of-fact and not reflective in nature. These kinds of questions were used for comparative purposes later in the interview. These questions also provided context for the student, giving the student more background and an understanding of their base person. Most questions however were more so in the moment and present.

In terms of chronology, the interview in the co-op term was conducted first and a follow up interview was conducted once the students returned to their school term. It was important that there were enough experiences to explore and discuss; with this in mind, the interviews were scheduled when enough time had elapsed in each term.

The interview process was semi-structured, with more focus on it being conversation-based. A base script of questions was loosely followed but no concrete line of questions was carried throughout the interviews. This allowed for a more natural progression of conversation and gave the interviewer the power to navigate the conversation in different directions. All the conversations were recorded and transcribed for further analysis. The conversations were transcribed using Otter and Temi.

Loosely following a process described by Aditya Johri in the Cambridge Handbook of Engineering Education Research [3], the analysis was multi-prong. Initially, the data was manually skimmed and highlighted, described as the "triangulation" phase. Once the basic ideas were understood from each interview, they were individually imported and analyzed using NVivo 12 . The first round, described as the "free" code, was focused on picking out the major skills for each student and what may overlap [3]. Next, this information was recorded according to emerging 
common themes, with the division mainly being locationbased. This "axial" coding was used for comparative and analytical purposes. This is explored in the results portion of this paper. Each case was then compared in the discussion section of this paper.

\section{LITERATURE REVIEW}

Haddara and Skanes explored the evolution of coop programs over the years and pointed out that there is a stark difference between what is deemed as "experience" and "experiential learning [2]. Although Rowe outlined what is required for a successful program, there is still a lack of understanding of what skills are specifically gained from such programs, as well as where they may derive from and how a student may apply this knowledge. They went into analysis of various benefits and perceptions of key stakeholders and recommended changes that could improve a student's experience [2].

The importance of systematically analyzing the gains from a co-operative program is vital in understanding the effects of the program on a student and this is explored by Venville, Lynch and Santhanam [4]. They found that routinely checking in with students and helping with their development helped gain an understanding of what they experienced [4]. The effects of work-integrated learning on a student's academic performance (ie their GPA and performance in school evaluations) has been explored by Blicblau, Nelson and Dini and Driffield, Foster, and Higson [5], [6]. The need for reflection-based feedback has been focused on by Doel; in this report, it was reported that weekly, reflection-based evaluations filled out by students helped guide students in understanding their experiences [7]. Johnston and McGregor mentioned Nieragden's suggestion that professional skills can be categorized as the following: self-management; interaction; communication; and organization, highlighting some of the skills already studied to be vital for a coop placement, but did not explore the origins or application of these skills in different contexts [8]. They also mentioned that when considering the applications of skills as they relate to ethics and social responsibility the "process of learning is as important as outcome" [8] This indicates the emergence of different motivations through coop programs, but does not track it or deeply analyzes its practicality.

The gaps outlined above are the motivation for this research. This paper aims to fill these gaps, by tracking skills through various terms and shedding light onto which skills are transferable between coop and school.

\section{RESULTS}

\subsection{Student 1}

Student 1 was in the transition between their second and third year of mechanical engineering when going into their co-op term and the follow up interview was conducted in their third year. Some of the major skills this student mentioned applicable for the workforce were time management, communication, initiative and responsibility. When asked about academic skills, the student put more emphasis on time management but in co-op this focus was on communication. Despite time management being one of the key skills applied in school, this student pointed out a disconnect between school and work:

"[what] is due today doesn't actually have to be due today unless it's a contractual obligation... you need to actually finish [the work] and do it right the first time"

This student does not claim that by lacking a due date they do not complete the work; instead they seem to highlight the idea of good versus fast work. Instead of managing due dates and deadlines, the student discussed management of tasks and deliverables. This is a specific shift in focus, in terms of time management. The student did go on to say that time management was generally a transferable skill between school and work, claiming that if a student was good at in school, they'd thrive in co-op.

Regarding communication, the student spoke about how rare good communication skills were at any level, and the balance that needed to be struck between "professional, personal and regular communication" in their co-op workplace. This balance was far more discussed in relation to co-op, with very little focus put on it in school. In particular, this student highlighted the practise of responsible socializing at work. Because they were in a professional setting, a larger variety of contexts existed for them to communicate in, which meant that although casual conversations were important, the onus was on the student to be responsible and professional enough to know their limits. The student discussed the lack of formal training/ teaching put into communication for them. This was an interesting point; in Lassonde (the school this student is enrolled in), there is a variety of courses discussing communication, whether it be written or verbal, and professional or casual. This conversation seems to indicate a lack of transferability of communication between school and co-op. Although both places utilize them extensively, the application of them seem to be rather different and it may be the case that the focus of these courses is not very applicable outside of school. The communication applied in co-op did seem to transfer nicely back into school, as the new understanding of different kinds of communication was applicable in school as well.

This student spoke about initiative and its relation to responsibility in the workplace. When they'd complete their assigned job, they would ask for new tasks, so as to not waste time. This was not something discussed in relation to school. Also, the motivation for studying in school was derived from enjoyment, as opposed to responsibility. As this student discussed, they enjoyed the content of their studies and the multifaceted nature of it. In work, they don't speak about passion as much as they do about responsibility. Nothing indicates that one form of motivation is better or worse than the other. Interestingly, in both scenarios the student described enjoying "the parts 
of your academics that allow you to see a visible end product". This statement seems to indicate that it is not necessarily responsibility that motivates good work, but the desire for a valuable end product is just as important. This shows that the motivation was transferable to co-op, originating from school.

In terms of technical skills, student 1 did mention a lot of their technical tasks when asked but maintained that they found more importance in their general skills. This was the case for school and co-op. This student mentioned that they worked with various team members to maximize efficiency in designs and worked with technical data, such as spec sheets, in their co-op meetings. They also mentioned that "programming is a high, very big skill" in the workforce. Finally, they mentioned that data analytics was something they needed to learn in their work term. Many of these skills were self-taught during co-op, but their general base knowledge from school did transfer enough to set a foundation. Not many of these skills transferred back to school, as the difference in context and focus made these new skills rather difficult to relate back. One thing this student did relate was the application to "memorize and adapt and learn" to school. Although specific knowledge did not transfer directly, this skill did.

\subsection{Student 2}

Student 2 was also in their second-third year transition when going into their co-op, and the follow-up was conducted in the middle of their third year. One interesting point this student mentioned was the expectation they had for their co-op. They indicated that they were under the impression that co-op would be theoretical, like school but were surprised to find the intense application involved. One major difference they brought up was this:

"I guess the big aspect that was different is seemed more individual and technical in school; it's more application skills in the workforce and you get to work with more of like a team"

Some of the major skills focused on by this student were communication, time management, organization and initiative. They also discussed the impact of responsibility and consequences.

One major skill necessary for co-op seemed to be communication. This student credited their communication skills to school, saying they treated their new co-op environment like "it was another group project". A clear transition can be seen from school to co-op in his regard. Taking a further look at the co-op context, this student spoke about communication as casual and follow-up conversations and talking to clients, contractors, teammates, and managers. Another factor of this was the content being communicated. co-op involved technical conversations about the business aspect of the job and this student reported learning through communication; every time this student would speak to a new client or company, they ended up "learning all the different aspects". Also, the student reported that they used different media for communication: through email, telephone, in person and in meetings. Across all platforms and audiences, this communication was "a bit more professional" than what they had experienced in school. When asked about school, the main form of communication was group communication, but this was never necessarily compared to co-op. Although communication was highlighted as a major skill, details such as whether this communication was group based, professional or casual were never compared or discussed in relation to school. This indicates that a basic level of communication was transferred from school, but it was further developed in this student's coop work term. Also, the improved communication broadened the student's perspective of communication, and they were about to transfer this skill back to school.

Time management and organization were named the most important in school and were rather relevant in this student's workplace. In the school context, time management was illustrated in terms of task assignment and prioritizing. Although it took some time to fully develop, once this student started applying it to the new context, it was applicable to work too. They found that they "could identify quickly what [they] had to do from the task and then act on that". Furthermore, this skill was significantly altered and improved during co-op; this student reported that they felt they had better organizational skills after co-op than they did during, because they had learned how to apply it all properly during their work term. Once they returned to school, they knew what their limits were in terms of workload and what they could handle. This insight provides an interesting path for the skill development, showing its transferability from and back to school. Although they entered into co-op assuming they had done a great job with organizing, the change in context meant relearning and reapplying. And so, when using their organizational and time management skills to school, they applied what they improved on in coop and what they retained from school.

This student connected their use of initiative to the responsibility they felt to their company. They spoke about the fact that one mistake or delay would cost more than just one person a trivial price; it could cost a company a substantial amount of money. There was also a responsibility they felt to their clients and coworkers. This meant that this student would ensure that parts and tasks would be completed on schedule, even if that meant extra emails or phone calls. Furthermore, they found that in school, passion is what drove their progress. In co-op however, it was the responsibility they had towards their co-workers, company and clients that motivated them to get work done. And even if it wasn't something they enjoyed, they had to do it. There was one occurrence of this in school: when the student spoke about group projects. They mentioned that the responsibility they had to their teammates would pressure them to perform at their best, even though they may not enjoy the topic at hand. Because this was recorded during the co-op term, it can be assumed 
that this skill may have originated in school, but it applied quite a bit more in this new context. After co-op, the student had a switch in mindset, having realized that they need to depend on themselves to perform at their best, even if there weren't other dependants. And so, they were no longer motivated by solely by passion in school, but by responsibility as well. This kind of attitude and growth in their responsibility skill can be traced from co-op to school

This student mainly focused on general skills, and only discussed technical ones when directly asked. Although their job was not non-technical by any means, they found that the general skills were far more applicable. Some of the major technical skills they applied in their co-op were 3D modelling and drawing, financial analysis and electrical and control systems analysis. Very little of this was traced from school- they actually found that school was inaccurate in its portrayal of the technical-general balance. They expected their co-op to be as technical as school was but found that co-op was far less so. Many of the technical skills they learned through their co-op did not transition well into their school, as the difference in context made it difficult to find applications. The student reported a lot of self-learning through their co-op experiences. In school, they mentioned that although a huge chunk of their time was spent on learning technical information, they spent a majority of their conscious efforts developing their general skills. This indicates that this student put more focus on general skills in their education, as opposed to their technical skills.

\subsection{Student 3}

Student 3 was in their third-fourth year transition when they went on their co-op term, and the follow up interview happened when they returned in their fourth year. Initially the major skills discussed by this student were time management, problem solving and communication. In the follow up interview, the student focused a lot more on responsibility and initiative, along with the previously listed skills. They also focused a lot less on technical skills.

In general, this student said that when they weren't applying their technical skills at work, they would be communicating. In student 3 's case, communication in school was casual and less hierarchical. In co-op, it was more formulaic and constantly professional, with most conversations happening with managers or top-level engineers. In school, communication that was professional would be limited to professors and TA's. Otherwise, it would be casual conversations between students. In co-op, especially in the beginning, this student spent very little time communicating with co-workers and only presented their technical work on occasion. This professional communication skill was transferred from school, connecting it to how they would speak to professors. As their co-op progressed, a lot more communication was required. They developed the skill to be concise and learned to communicate through a network of engineers, managers and clients. Although this student did not integrate casual conversation in to their co-op experience, the development that came from this progression translated well when returning to school. Communication with professors and students did not change, but the improved communication did apply in the changed context.

For time management in co-op, this student mentioned that they had to manage several tasks on an everyday basis. This meant that they would have to prioritize and allocate their time accordingly. They also mentioned that this was something they had done a lot of in school, specifically in relation to assignments. This then translated well into coop. From co-op, this student reported not necessarily changing this skill, but improving on it. They found that after co-op, they were better at prioritizing tasks according to deadlines and importance. Although the skill did not originate in their co-op placement, they were able to improve on it and transfer it back.

Another thing this student brought up was problem solving. They made an effort to mention that in co-op, problem solving was not linear or well defined. When tasked with a job, they were required to speak to different people and learn as much as they could. For the next tasks, they would have "to go through them a completely different way" and that was the way tasks were handled. This student described problem solving in school as far less complicated and highlighted a big divide between school and co-op in that regard. The new skill could theoretically be transfer to school, in specific for design courses.

As this student's co-op progressed, they were given a lot more responsibility and when the work they did was "pretty important, compared to the beginning", they "felt confident doing the work". This also showed an increase in general skills used by this student. In the follow-up interview, spoke about impact in relation to co-op. This makes an interesting connection between task assignment and a boost in confidence. This student found that once they were motivated by impact, they would complete tasks more fully and properly. They realized that their efforts would impact not just themselves, but the company as a whole. The idea of being part of something bigger was a driving force for asking for extra work. This did not seem to transfer from school, it did seem to connect in school. In specific, this student spoke about capstone projects and the fact that them being so multifaceted allows students to be motivated by the impact their project can make. For example, this student spoke about sponsors and how the responsibility a team has towards their sponsor shows the impact of their actions. This analysis made it clear that the student did see a potential for transferability.

In the beginning of their co-op, student 3 talked a lot more about their technical skills: 3D modelling and drawing and tool identification and sorting. They even said that they spent a lot less time working on general than technical. This seemed to change as time went on, with the student spending more time on general skills than before. In school, the student mentioned that even though the technical skill were taught, they were taught at a shallow level and that meant that application would require a substantial amount of self-teaching, specifically in regard to 3D modelling. This student did mention the 
transferability of their technical skills back to school, specifically because the software used by their company was the same as the one used in school.

\section{DISCUSSION}

\subsection{Similarities Across Cases}

All three students mentioned that communication, time management and responsibility were applicable to their coop experience, and that these skills were generally transferable to and from school. Although the details of their application of these skills differed with each case, these skills were present throughout. This consistency does highlight the major skills that could be widely transferable in other cases, if a more comprehensive and large-scale study were to be conducted. Because little research has been done in the transferability of skills, this data cannot currently be totally validated. The specific skills are in line with the literature available today. As mentioned, skills such as self-management, interaction, communication and organization were found to be applicable professional skills [8]. This agrees with the skills that were highlighted in this project. In another paper, Rampersad and ZicoticKukolj tracked the progress 5 skills throughout their work integrated learning experience: communication, problem solving, critical thinking, teamwork and innovation [9]. Directly, this research agrees with Rampersad et al. in regard to communication and problem-solving skills Indirectly, skills such as critical thinking and teamwork can easily be connected to time management and responsibility, also agreeing with Rampersad's findings [9]. This shows that the findings of this paper, although just a reflection of a select few students, is in line with previous studies done.

In all three cases, the students spent a lot more time discussing the nuances of their general skills, as opposed to their technical. Out of three students, only one found an easy connection between school and co-op in their technical skills. And even in this case, student 3 did not find their base skill level from school sufficient enough to transfer to co-op. This shows that because co-op placements tend to be so unique, from school and even other co-op placements, transferability of technical skills is quite difficult and rare. Only in specific circumstances are these kinds of skills applicable. For example, student 1 and 2 mentioned the financial aspect of their work. This did not transfer to or from school. Although important for their work, the skill did not apply to anything beyond their coop experiences. Each student did bridge their gap by practising self-learning, to complete the tasks they were assigned. This does raise an interesting point mentioned by student 1: the lack of diversity in their education. After doing co-op, each student realized that work entails an understanding of more than the theoretical knowledge of their major. This indicates a gap in their educational experience but is outside the scope of this project. It may be rewarding to take a closer look at this pattern in a project in the future. Finally, students 1 and 2 both claimed that general skills were more widely practised in co-op than technical, and student 3 was following this trend as their co-op progressed. With this in mind, a conclusion can be made that general skills are more applicable and transferable through co-op than technical.

Students 2 and 3 both made a connection between clubs and co-op work terms. Whether this connection existed for student 1 is unknown, as they did not offer insight in this regard and the other interviews happened following student 1 , so the chance to ask did not arise. Not every skill transferred to school directly, but these students found that some skills did apply to their club involvement. Student 2 specifically mentioned how co-op helped them gain a managerial perspective that really helped in club management. Student 3 also made connections from their co-op to their club involvement, specifically when they spoke about impact. Although they did not find any transferability of impact to school work, they did find it in their clubs. They also mentioned that they would like to join more clubs ever since returning to school, to further develop their skills. To some extent, this student did hint that the initiative they learned to apply in their co-op may have motivated this interest in clubs, but this was not explored further. In general, this relationship tracing to clubs provides an interesting insight into what should be understood to be included in the educational experience. In the beginning of this project, the impact of extracurriculars was not considered and they were not explicitly included in what was considered "school". But for students involved in extracurriculars, their involvement is an integral part of their education. This means that when trying to understand skills as they pertain to a student's education, extracurriculars should be valued and studied as a form of valuable information.

All of the students made a connection between the success of their co-op experience and initiative. They mentioned that initiative rarely existed in school, and there was very little space to allow for transferability to school after it was acquired in co-op. Student 1 mentioned that they would take advantage of simple things such as inoffice casual conversations to advance their network and learn about the company, something not ever practised in school. Student 2 even explicitly said that "initiative goes further at work than it does in school". Student 3 discussed how it was asking for tasks that get them more responsibility, but because of how busy school is, they could not continue this practise. It was a sentiment echoed across all three cases. The fact that initiative was in general a non-transferable skill, despite it being vital in each student's co-op success, raises a question as to whether this gap should be explored in the current curriculum. There are clear benefits to initiative, in particular the responsibility and sense of impact and purpose that comes with it. On the other hand, it could be worth studying the motivations surrounding extracurriculars, and if the development of initiative can be related to decisions such as joining clubs. This is mentioned here because both students 2 and 3 
discussed the applications of skills (although not specified) to their extracurricular involvement.

As mentioned briefly above, there was a connection between initiative and responsibility. All of the students, to some extent, seem to have made this connection. One derivation from this is the idea of motivation. As discussed above, both students 1 and 2 directly mentioned that in school, they are motivated by the passion they have for the subject. There was no sense of responsibility driving their academic endeavors prior to co-op, but once they entered their placement, they would complete the less enjoyable tasks to the same proficiency as they would all their other tasks. When asked about what drove this, they both, in their own way, connected it to the responsibility they had. Student 2 even discussed how they disliked financial work but got through it because it had to be done. And even though the benefit of a final product did feel great upon completion (which transferred from school), both students discussed this new motivation and its transferability to school.

Finally, all the students mentioned problem solving as a new skill in their co-op. Students 1 discussed it in regard to focus and diligence, because solutions were no longer one or the other and they would have to do multiple readings to find simple answers. Student 2 said something similar, connecting their initiative to problem solving; to find the best product or to file the most accurate claims, this student would have to go out of their way to find creative ways to get their tasks done. This does indicate the use of skills like diligence and persistence. Also, , student 3 discussed -most directly- the complicated network they had to navigate once they entered co-op to solve a problem, something that was not present in school. Therefore, it seems that for each student, problem solving skills from school did not apply too well to co-op, but the acquired skills in co-op did transfer well to school after the fact. Furthermore, Johnston and McGregor found that students found the "process of learning [to be] as important as the outcome" [8]. This finding agrees with the testimonies of the students in this research, as problem solving skills seem to become a vital tool in coop, and the focus shifts from the outcome to the process, through the development of this skill.

\subsubsection{Differences Between Cases}

Due to environmental discrepancies between each case, the nuances of each skill were different. For example, student 1 emphasised the usefulness of socializing, while student 3 had very little socializing in their co-op placement. Also, each company these students worked for seemed to handle different streams of even mechanical engineering, from HVAC to part designing. Due to technical differences, the applicable skills were drastically different in some cases. For example, students 2 and 3 mentioned 3D modelling as a major technical skill, while student 1 spoke highly of programming, something the other students did not even mentioned.

\subsection{Limitations}

It is important to mention the limitations of this research. Phenomenological research focused on the lived experiences of people, we presented as case studies of three participants. The story of each participant has validity and meaning on its own, and although we identify common themes among the participants, we do not make conclusions that are generalized for a particular population. As mentioned above, each student's co-op workplace was very different and that means that their experiences are shaped by the context of their workplaces. This means that comparisons between students are impacted by differences in their workplaces. Therefore, the data embodies both the students school experience and the co-op placement. In order to deconvolute the data, the questions in the interviews were clear and background for each student was found. This made separation easier in the analysis phase.

Furthermore, due to the nature of a semi-structured interview, follow up questions were posed as interviews occurred and themes emerged. This meant that some interviews went more in depth into some topics that other interviews did not. This was mitigated by the free coding that happened as interviews went through. This meant that some of these themes could be explored in the second interview, as opposed to there being a gap in the data at the end.

Finally, multiple researchers worked on this project. The follow up interviews for a couple of the cases were conducted by a different researcher than the initial interview. This means that could be minor discrepancies in the intentions between the researchers, which would be present in the questions asked. When the second researcher took over, they did so with a very similar research question guiding them and many of the questions asked were modelled after the questions posed previously. This allowed to a smooth transition but may lead to gaps in the data. And because analysis is very person-oriented, those biases were kept in check and were maintained consistent through every interview, even the ones not conducted by them.

\section{CONCLUSION}

Through each of the case studies, the following skills were found to be most transferable: communication, time management, organization, problem solving and responsibility. All three cases agreed that general skills, such as the ones listed above, were far more transferable than their technical skills, to and from school. Skills such as communication, time management, organization and responsibility seemed to transfer well from school into coop. Each skill was then improved on and then applied back into school, especially in specific cases.

Problem solving was one skill that seemed to have very little transferability from school but was learned and applied to such a great extent, it was, to some degree, transferred back to school. Students did mention that there 
was very limited space available for it to be applicable, but it was possible, especially to extracurriculars and clubs. Also, although not directly applicable, there was quite an emphasis by each student on initiative and it connection but it was not a skill they found transferable from their coop. These are two gaps identified in these cases, which may be interesting to explore further.

\section{Acknowledgements}

Zachary Matthews worked as a researcher on this project up to September 2018. Data from his research has been incorporated into the analyses in this paper. The authors gratefully acknowledge his contributions.

This work has been approved by the York University Research Ethics Board, with certificate number e2018178.

\section{References}

[1] Cooperative Education and Work-integrated Learning (CEWIL) Canada. "About Us". Internet: https://www.cewilcanada.ca/about-us.html [Jan. 10, 2019]

[2] Mahmoud Haddara and Heather Skanes. "A reflection on cooperative education: from experience to experiential learning". Asia-Pacific Journal of Co-operative Education, vol. 8(1), pp. 67-76, June 18, 2007. Available from https://www.ijwil.org/files/APJCE_08_1_67_76.pdf

[3] Aditya Johri, Cambridge Handbook of Engineering Education Research. "Chapter 28: Conducting Interpretive Research in Engineering Education Using Qualitative and Ethnographic Methods". Cambridge, UK: Cambridge University Press, 2014, pp. 558-562
[4] Annie Venville, Bernardine Lynch and Elizabeth Santhanam. "A systematic approach to the evaluation of the student experience in work-integrated learning". International Journal of Work-Integrated Learning, vol. 19(1), pp. 13-21, 2018. Available from

https://www.ijwil.org/files/IJWIL_19_1_13_21.pdf

[5] Aaron Simon Blicblau, Tracey Lousie Nelson and Kurosh Dini. "The role of work placement in engineering students' academic performance". Asia-Pacific Journal of Cooperative Education, vol. 17(1), pp. 31-43, 2016. Available from https://files.eric.ed.gov/fulltext/EJ1114038.pdf

[6] N.L. Driffield, C.S. Foster and H.E. Higson. "Placement and degree performance: Do placements lead to better marks, or do better students choose placement?" in ASET Annual Conference, Mark Hart, et. al (ed.) (Leeds, England; 6-8 Sept, 2011), 24 pp., 2011. Available from http://publications.aston.ac.uk/18824/1/Placements_and_degre e_performance.pdf

[7] Susan Doel. "Fostering student reflection during engineering internships". Asia-Pacific Journal of Cooperative Education, vol. 10(3), pp. 163-177, 2009. Available from https://www.ijwil.org/files/APJCE_10_3_163_176.pdf

[8] Stephen Johnston and Helen McGregor, "Recognizing and Supporting a Scholarship of Practice: Soft Skills are Hard!" Asia- Pacific Journal of Cooperative Education, vol. 6(1), pp. 1-6, 2005. Available from

https://www.ijwil.org/files/APJCE_06_1_1_6.pdf

[9] Giselle Rampersad and Vlatka Zitvotic-Kukolj, "Workintegrated learning in science, technology, engineering and mathematics: Drivers of innovation for students".

International Journal of Work-Integrated Learning, 19(2), 193-204, 2018. Available from

https://www.ijwil.org/files/IJWIL_19_2_193_204.pdf 